\title{
Coming together - symbiont acquisition and early development of Bathymodiolus mussels
}

\author{
Maximilian Franke ${ }^{1}$ Benedikt Geier ${ }^{1}$, Jörg U. Hammel ${ }^{2}$, Nicole Dubilier ${ }^{1,3 *}$ and Nikolaus Leisch ${ }^{1 *}$ \\ ${ }^{1}$ Max Planck Institute for Marine Microbiology, Celsiusstr. 1, 28359 Bremen, Germany \\ ${ }^{2}$ Helmholtz-Zentrum Hereon, Institute of Materials Physics, Max-Planck-Str. 1, 21502 Geesthacht, Germany \\ ${ }^{3}$ MARUM-Zentrum für Marine Umweltwissenschaften, University of Bremen, Leobener Str. 2, 28359 Bremen, Germany \\ * corresponding authors: nleisch@mpi-bremen.de, ndubilie@mpi-bremen.de
}

Keywords: larvae, aposymbiotic, morphology, symbiosis, host microbe interaction, invertebrates, bivalves, anatomy, $\mu \mathrm{CT}$, 3D

\begin{abstract}
Symbiotic associations between animals and microorganisms are widespread and have a profound impact on the ecology, behaviour, physiology, and evolution of the host. Research on deep-sea mussels of the genus Bathymodiolus has revealed how chemosynthetic symbionts sustain their host with energy, allowing them to survive in the nutrient-poor environment of the deep ocean. However, to date, we know little about the initial symbiont colonization and how this is integrated into the early development of these mussels. Here we analysed the early developmental life stages of $B$. azoricus, " $B$ ". childressi and $B$. puteoserpentis and the changes that occur once the mussels are colonized by symbionts. We combined synchrotron-radiation based $\mu \mathrm{CT}$, correlative light and electron microscopy and fluorescence in situ hybridization to show that the symbiont colonization started when the animal settled on the sea floor and began its metamorphosis into an adult animal. Furthermore, we observed aposymbiotic life stages with a fully developed digestive system which was streamlined after symbiont acquisition. This suggests that bathymodiolin mussels change their nutritional strategy from initial filter-feeding to relying on the energy provided by their symbionts. After $\sim 35$ years of research on bathymodiolin mussels, we are beginning to answer fundamental ecological questions concerning their life cycle and the establishment of symbiosis.
\end{abstract}

\section{Introduction}

Mutualistic interactions between hosts and their microbiota play a fundamental role in the ecology and evolution of all animal phyla. By associating with microorganisms, animals can expand their metabolic capabilities and colonize habitats they could not live in on their own [1]. A prime example for such symbioses are bathymodiolin mussels, which occur worldwide at cold seeps and hot vents on the ocean floor. Mussels of the genus Bathymodiolus house chemosynthetic bacteria in their gills, in cells called bacteriocytes [2]. In these nutritional symbioses, the bacteria use reduced compounds in the vent and seep fluids, to gain energy for the fixation of carbon and provide nutrition to their hosts. Two types of symbionts dominate Bathymodiolus mussels, sulphuroxidizing (SOX) symbionts, whose main source of energy are reduced sulphur compounds, and methane-oxidizing symbionts (MOX), which gain their energy from oxidizing methane [3].

The transmission of symbionts from one generation to the next plays a central role in the ecology and evolution of mutualistic associations. Symbionts can be transmitted vertically from parent to offspring, intimately tying them to the reproduction and development of their host. Alternatively, in horizontal transmission, symbionts are recruited each generation anew from the environment, entailing that the symbiotic partners are physically separate from each other before the symbiosis is established. In many hosts that rely on horizontal transmission, the acquisition of symbionts induces drastic morphological and developmental changes [4]. These can range from tissue rearrangement, as in the squid-vibrio symbiosis [5], to the development of an entirely new bacteria-housing organ, like the trophosome in the hydrothermal vent tubeworm Riftia pachyptila [6].

Although Bathymodiolus mussels have been studied for over 35 years, very little is known about how their symbionts are transmitted, at which developmental stage the symbionts colonize the mussels, and how symbiont acquisition affects the development and body plan of the mussels [7]. It is assumed that the symbionts are transmitted horizontally, based on phylogenetic studies that showed a lack of cospeciation between hosts and symbionts, and morphological studies in which symbionts were not observed in the mussels' reproductive tissues [8-11]. In closely related "Idas" mussels, light and fluorescence microscopy analyses showed that these remained aposymbiotic until the juvenile stage, indicating horizontal transmission in these species [12, 13]. However, definitive evidence of an aposymbiotic early life stage of Bathymodiolus mussels is lacking. The earliest life stages found so far were in the late larval phase, and these were already colonized by symbionts, with a well-developed symbiotic habitus that was indistinguishable from adult mussels [14]. Given that early life stages of aposymbiotic Bathymodiolus have not yet been described, fundamental questions in the acquisition of symbionts in these hosts have remained unanswered, including at which developmental stage the mussels acquire their symbionts, if the SOX and MOX symbionts colonize their hosts at the same time, and which developmental changes occur in the mussels at the onset of symbiont colonization.

In this study, we were fortuitous in discovering very early, aposymbiotic life stages of three Bathymodiolus species, two from hydrothermal vents on the Mid-Atlantic Ridge (MAR), B. puteoserpentis and B. azoricus, and one from cold seeps in the Gulf of Mexico, " $B$ ". childressi (also referred to as Gigantidas childressi e.g. [15]). We used a correlative imaging approach by combining synchrotron-radiation based micro-computed tomography $(\mathrm{SR} \mu \mathrm{CT})$, correlative light $(\mathrm{LM})$ and transmission electron microscopy (TEM), and fluorescence in situ hybridization (FISH) to analyse the early life stages of Bathymodiolus mussels and compare them to their shallow-water relatives, the blue mussel Mytilus edulis [16]. This approach allowed an integrative analysis from the level of the whole animals down to single host and symbiont cells of the processes involved in symbiont colonization and its effects on the host body plan $[17,18]$.

\section{Methods}

\section{Sampling and fixation}

All deep-sea mussels were collected with remotely operated vehicles: B. puteoserpentis from the Semenov vent field on the MAR at 2447 $m$ depth with the German Research Vessel (RV) Meteor during cruise M126 in 2016, B. azoricus from the Bubbylon vent on the MAR at 1002 m depth during the RV Meteor cruise M82-3 in 2010, and " $B$ ". childressi at the Mississippi Canyon site 853 in the Gulf of Mexico at 1071 m depth with the RV Nautilus (Ocean Exploration Trust) during cruise NA58 in 2015 (detailed information in Table S1). M. edulis were collected in the Baltic Sea at a site close to Kiel, Germany (54.394 N, 
$10.190 \mathrm{E})$ at $1.5 \mathrm{~m}$ water depth. Upon recovery, specimens were fixed for morphological analysis and FISH in $2 \%$ paraformaldehyde (PFA) in phosphate buffer saline (PBS), and for morphological analysis and TEM in $2.5 \%$ glutaraldehyde (GA) in PHEM buffer (piperazine-N, $\mathrm{N}^{\prime}$-bis , 4-(2-hydroxyethyl)-1-piperazineethanesulfonic acid, ethylene glycolbis( $\beta$-aminoethyl ether and $\left.\mathrm{MgCl}_{2}\right)$ [19]. After fixation, samples were stored in the corresponding buffers (PFA: ethanol/PBS; GA: PHEM).

\section{Shell measurements}

Mussels were photographed with a stereomicroscope (Nikon SMZ 25, Nikon Japan) equipped with a colour camera (Nikon Ds-Ri2, Nikon Japan) and the software NIS-Elements AR (Nikon Japan). Measurements were recorded as shown in Figure S1c (Table S2) and shell margin limits were identified by their unique coloration (Figure S1d).

\section{Histological analysis}

PFA-fixed samples were decalcified with ethylenediaminetetraacetic acid (EDTA). For histological analysis, samples were post-fixed with $1 \%$ osmium tetroxide $\left(\mathrm{OsO}_{4}\right)$ for $1 \mathrm{~h}$ and embedded in low-viscosity resin (Agar Scientific, UK). Sections of 1.5- $\mu \mathrm{m}$ thickness were cut with a microtome (Ultracut UC7 Leica Microsystem, Austria) and stained with $0.5 \%$ toluidine blue and $0.5 \%$ sodium tetraborate. For TEM, semithin sections were mounted on a resin block, ultra-thin $(70 \mathrm{~nm})$ sections were cut on a microtome (Ultracut UC7 Leica Microsystem, Austria) and mounted on formvar-coated slot grids (Agar Scientific, United Kingdom) [18]. Sections were contrasted with $0.5 \%$ aqueous uranyl acetate (Science Services, Germany) for 20 min and with 2\% Reynold's lead citrate for $6 \mathrm{~min}$. For details see Supplementary Methods.

\section{Fluorescence in situ hybridization}

PFA-fixed B. puteoserpentis were dehydrated, embedded in paraffin and sectioned at 5-10 $\mu \mathrm{m}$ thickness on a Leica microtome RM2255 (Leica, Germany). Sections were de-waxed, rehydrated, and air-dried. FISH was performed using double-labelled specific probes targeting the 16S RNA of the SOX and MOX symbionts as well as a general probe targeting all bacteria (Table S3) [20]. For details see Supplementary Methods.

\section{Microscopy}

Light microscopy (LM) analyses were performed using a Zeiss Axioplan 2 (Zeiss, Germany) equipped with an automated stage, two cameras (Axio CAM MRm Zeiss and Axio CAM MRc5 Zeiss, Germany) and an Olympus BX61VS (Olympus, Tokyo, Japan) slide-scanner equipped with an automated stage and two cameras (Olympus XM10, Tokyo, Japan and Pike F-505C, Allied Vision Technologies GmbH, Stadtroda, Germany).

Fluorescence microscopy analyses were performed using an Olympus BX53 compound microscope (Olympus, Tokyo, Japan) equipped with an ORCA Flash 4.0 camera (Hamamatsu Photonics K.K, Hamamatsu, Japan) using a 40x semi-Apochromat and a 100x super-Apochromat oil-immersion objective and the software cellSens (Olympus, Tokyo, Japan), and a Zeiss LSM 780 confocal laser-scanning microscope (Carl Zeiss, Jena, Germany) equipped with an Airyscan detector (Carl Zeiss, Jena, Germany) using a $100 \times$ Plan-Apochromat oil-immersion objective and the Zen-Black software (Carl Zeiss, Jena, Germany). For details see Supplementary Methods.

Ultra-thin sections were imaged at $20-30 \mathrm{kV}$ with a Quanta FEG 250 scanning electron microscope (FEI Company, USA) equipped with a STEM detector using the $\mathrm{xT}$ microscope control software ver. 6.2.6.3123.

\section{SR $\mu$ CT measurements}

$\mathrm{SR} \mu \mathrm{CT}$ datasets were recorded at the Deutsches ElektronenSynchrotron (DESY) using the P05 beamline of PETRA III, operated by the Helmholtz-Zentrum Hereon (Geesthacht, Germany [21]). The X-ray microtomography setup at $15-30 \mathrm{keV}$ and $5 \times$ to $40 \times$ magnification was used to scan resin-embedded, $\mathrm{OsO}_{4}$-contrasted samples with attenuation contrast and uncontrasted samples in PBS-filled capillaries [22], with propagation-based phase contrast. Scan parameters are summarized in Table S4. The tomography data were processed in Matlab. Custom scripts implementing a TIE phase-retrieval algorithm and a filtered back projection, implemented in the ASTRA toolbox, were used for the tomographic reconstruction [22-25]. SR $\mu \mathrm{CT}$ models were used to ground truth the volume calculations from histological section series by measuring sectioning-induced tissue compression, which was on average $7 \%$.

\section{Image processing and 3D visualization}

Histograms and white balance of microscopy images were adjusted using Fiji ver. V1.52p and Adobe Photoshop CS5 and figure panels were composed using Adobe Illustrator CS5 (Adobe Systems Software Ireland Ltd.). LM-images were stitched and aligned with TrackEM2 [26] in Fiji ver. V1.52p.

Threshold-based and manual segmentation were used to generate 3D models from LM and $\mu \mathrm{CT}$ datasets from representative individuals in Amira 6.7.0 (ThermoFisher Scientific). Co-registration between $\mu \mathrm{CT}$ and LM datasets and between LM and TEM datasets was carried out in Amira [18]. For details see Supplementary Methods.

\section{Results}

We analysed developmental stages of three species of Bathymodiolus mussels from aposymbiotic pediveligers to symbiotic adults, to determine at which stage the symbionts colonize their hosts and reveal the developmental modifications that these mussels have evolved to adapt to their symbiotic lifestyle (Figure 1). Because the names for larval stages of bivalves have not always been used consistently, we here define the stages we analysed. The earliest life stages in our study were at the last planktonic larval stage - the pediveliger. Once settled on the seafloor, the animal initiates its metamorphosis from a planktonic to a benthic lifestyle and enters the plantigrade stage of development. While metamorphosing, the plantigrade degrades the velum, the larval feeding and swimming organ, and develops into a post-larva. During the post larval stage, the animal secretes the adult shell and once the ventral groove of the gills is formed [27], it enters the juvenile stage. Once the gonads have developed, the mussel becomes an adult [16].

\section{Identification of developmental stages}

We analysed 259 Bathymodiolus individuals from three species that ranged from $370 \mu \mathrm{m}$ to $4556 \mu \mathrm{m}$ shell length (129 B. puteoserpentis, 124 B. azoricus and 6 " $B$ ". childressi; Table S2, Table S5). The earliest developmental stages we recovered were pediveligers, with shell lengths of $366 \mu \mathrm{m}$ to $465 \mu \mathrm{m}$. However, shell dimensions alone were not sufficient for distinguishing between developmental stages, which could only be identified through detailed analyses of the mussels' soft body anatomy (Figure S1a and b). These morphological analyses revealed that the shell sizes of 58 pediveligers and plantigrades overlapped with those of the smallest post-larva stages (Figure S1f).

\section{Morphological characterization of Bathymodiolus developmental stages}

Among the samples we collected, B. puteoserpentis specimens were best preserved and covered the widest range of developmental stages. 
We therefore focussed our detailed morphological analyses on $B$. puteoserpentis, and compared these findings with selected $B$. azoricus and " $B$ ". childressi stages (Figure S2 and S3). In the following, we describe the shared morphological features of all three species, unless specified otherwise.
The pediveliger larvae were characterized by the presence of a velum (the larval swimming and feeding organ), a fully developed digestive system, a foot with two pairs of retractor muscles and two gill baskets (Table S6, Figure 1a and Video S1, Figure S4 a and d). The digestive system consisted of the mouth, oral labial palp, oesophagus, stomach, a

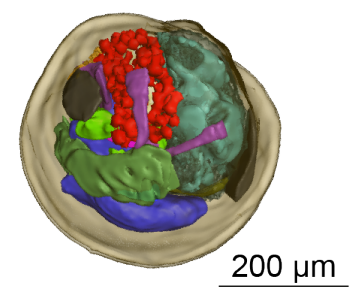

gill

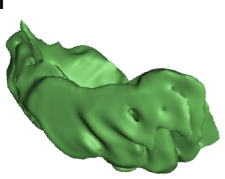

$100 \mu \mathrm{m}$

digestive system

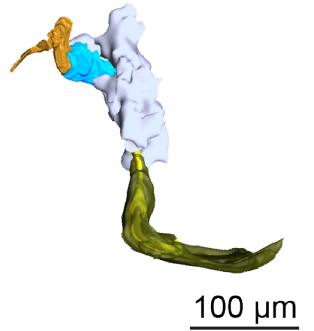

intestine

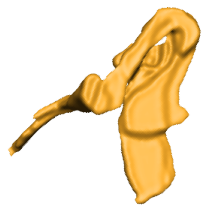

$25 \mu \mathrm{m}$

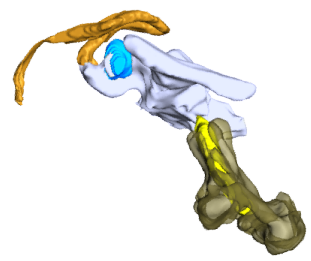

$100 \mu \mathrm{m}$

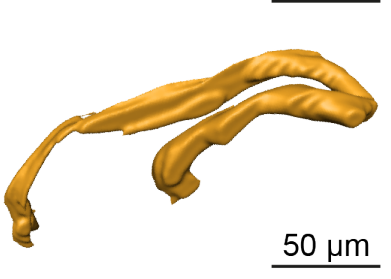

C
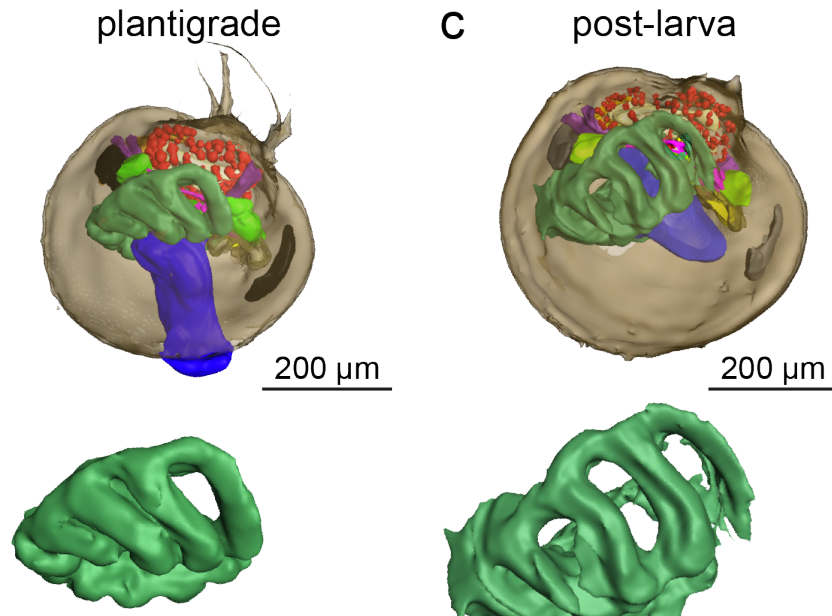

$100 \mu \mathrm{m}$
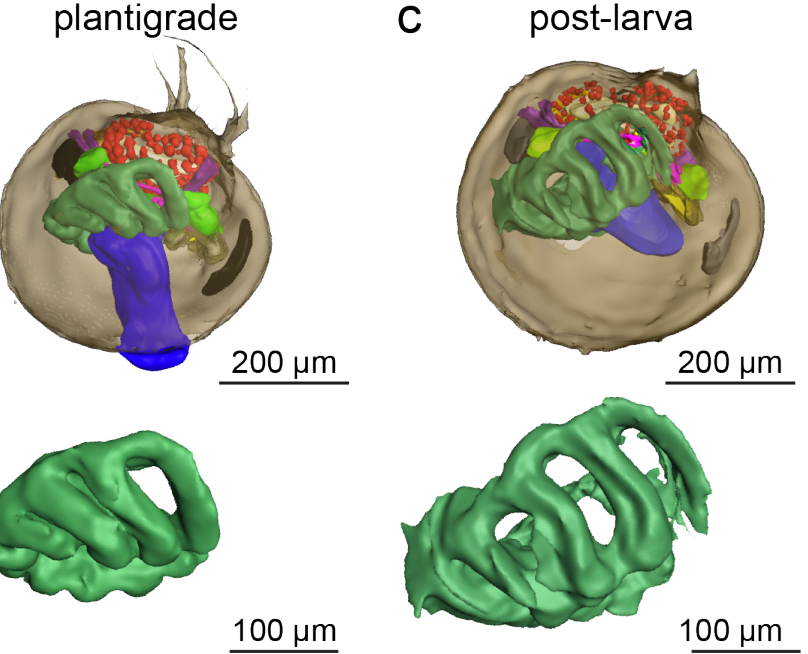

d juvenile / adult
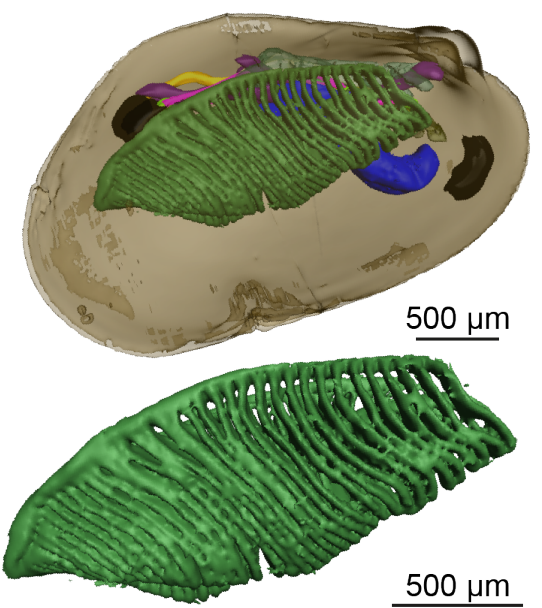

$500 \mu \mathrm{m}$
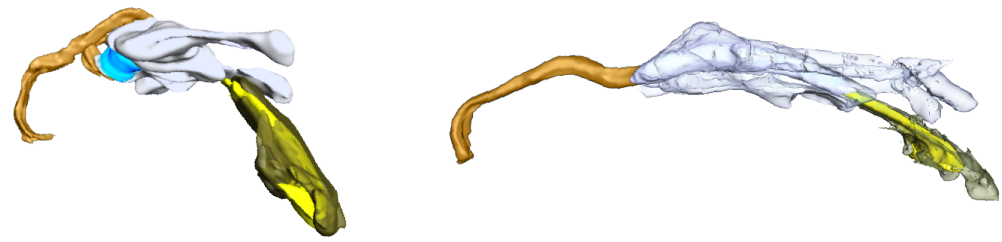

$100 \mu \mathrm{m}$
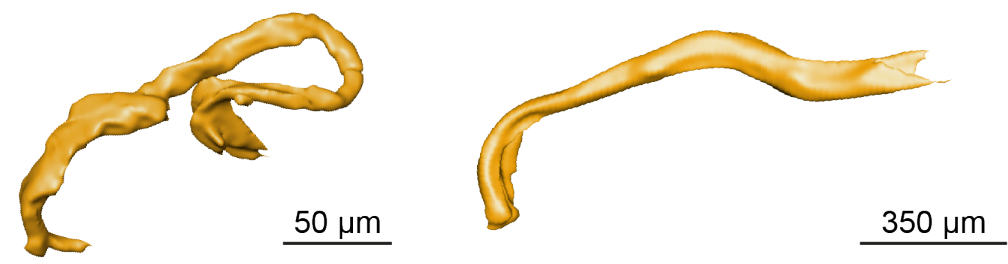

lipid vesicles

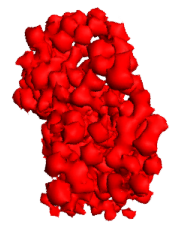

$100 \mu \mathrm{m}$

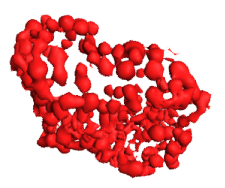

$100 \mu \mathrm{m}$

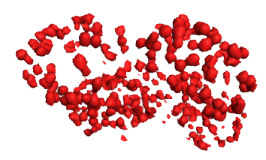

$100 \mu \mathrm{m}$

velum

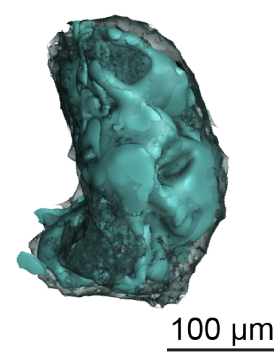

adductor muscle $\square$ foot $\square$ ganglia $\square$ gills $\square$ intestine
labial palps $\square$ lipid vesicles oesophagus $\square$ retractor muscle
style sac $\quad$ stomach and digestive gland $\square$ shell $\square$ velum

Figure 1 Three-dimensional visualization of $\boldsymbol{B}$. puteoserpentis developmental stages analysed in this study. Note the different scale bars in a-c and d. The three-dimensional data analysed was obtained by threshold-based and manual segmentation of histological section series and SR $\mu$ CT measurements. 
two digestive glands, gastric shield, the style sac with crystalline style, mid gut, s-shaped looped intestine, and an anal papillae (Figure 1a and Figure S5). The epithelial cells of the stomach contained membranebound lipid vesicles with an average diameter of $15.8 \mu \mathrm{m}$ (75 lipid vesicles measured in 3 mussels; Figure 1 and Figure S5). The gill baskets on each side of the foot (Figure 1a and Figure S5) consisted of three to four single gill filaments in $B$. puteoserpentis and five in $B$. azoricus and " $B$ ". childressi (Figure S2 b and c). These filaments form the descending lamella of the inner demibranch in later life stages (Figure S5, Video S1). For further details, see Supplementary Note 1.

In plantigrades, the developmental stage after the pediveliger, the first steps of metamorphosis from a planktonic to a benthic lifestyle were visible in the degradation of the velum (Figure S4) and the appearance of byssus threads (Figure S6). In this stage, rearrangements of all organs occurred, for example, the alignment of the growth axis of the gill 'basket' with the length axis of the mussel (Figure 1a-c, Figure $\mathrm{S} 7$ and Video S2). The number of gill filaments increased by one in all species (B. puteoserpentis, 5; B. azoricus, 6; and " $B$ ". childressi, 6; Figure S3). Furthermore, gill filaments separated from each other, increasing the gaps between them from $47 \mu \mathrm{m}$ to $120 \mu \mathrm{m}$ (Figure 1c). These changes in gill morphology indicate a functional shift from a purely respiratory organ to a filter feeding and respiratory organ. In the digestive tract, the number and volume of lipid vesicles decreased from $12.8 \%$ of the soft-body volume in pediveligers to $3.9 \%$ in plantigrades, $1.5 \%$ in post-larvae (mean diameter $8.37 \mu \mathrm{m}, n=60$ ), and were no longer present in juveniles and adults (Figure 1a-d and Table S6). The post-larval stage began once the mussels secreted the dissoconch and completed metamorphosis (Figure S1 and Figure S8). As the mussels transitioned from the post-larval to the juvenile stage, the digestive system straightened (Figure 1c-d, Figure S9 and Video S3 and S4). This morphological change was most prominent in the intestine, which went from a looped to a straight shape and remained straight in all later developmental stages (Figure 1c-d and Figure S9). For further details see Supplementary Note 2.

\section{Establishment of the symbiosis}

Central to an accurate assessment of symbiont colonization and symbiont-mediated morphological changes was our combined approach of correlative SR $\mu \mathrm{CT}$, FISH, and light and electron microscopy (Video $\mathrm{S} 5$, Figure S10). This allowed us to rapidly screen whole animals yet achieve the resolution needed to identify the colonization of single eukaryotic cells by symbiotic bacteria. We first searched for a morphological characteristic that was visible using light microscopy and reliably revealed the presence of symbionts in host cells. Previous studies [28, 29] showed that in juvenile and adult Bathymodiolus mussels, the morphology of epithelial cells colonized by symbionts is remodelled: i) The microvilli that cover all epithelial cells are lost (known as microvillar effacement), and ii) epithelial cells become hypertrophic (swollen) compared to aposymbiotic cells. We identified a third characteristic change in epithelial cells colonized by symbionts that has not received much attention, namely the loss of cilia (Figure 2 $\mathrm{c}, \mathrm{f}$ and i). We tested if these three morphological characteristics had predictive power for symbiont colonization by analysing 1813 epithelial cells from a subset of six B. puteoserpentis individuals (2 pediveliger, 1 plantigrade, 3 post-larvae) and comparing LM images of these cells with their correlated TEM images (average cell count per sample 302). Our analyses showed that all cells predicted to have symbionts in the LM dataset were indeed colonized in the TEM dataset, and likewise, all cells predicted to be aposymbiotic were free of symbionts (Figure $\mathrm{S} 10$ ). We next used our verified morphological characters to reveal the onset of colonization in $B$. puteoserpentis in the subset of six mussel individuals. All pediveliger cells were free of symbionts $(n=797$ host cells in 2 pediveliger). In plantigrades $15 \%$ and in post-larvae $23 \%$ of all analysed gill, mantle, foot and retractor muscle epithelia cells were colonized by symbionts ( $n=336$ host cells in 1 plantigrade; $n=680$ host cells in 3 post-larvae). Finally, we expanded our analysis to LM analyses of serially sectioned individuals, and these confirmed our results from the correlative dataset (all pediveligers were aposymbiotic, $n=5 ; 50 \%$ of the plantigrades were colonized by symbionts, $n=6$; all post-larvae were colonized by symbionts, $\mathrm{n}=5$ ).

Expanding our analyses to all three Bathymodiolus species, we found that the pediveligers of all three host species were aposymbiotic (Figure $2 \mathrm{a}, \mathrm{d}$ and g). Interestingly, two of the aposymbiotic B. puteoserpentis pediveligers had bacterial morphotypes similar to the SOX and MOX symbionts attached to the outside of their shell (Figure S11). The next developmental stage, the plantigrades, were the earliest developmental stage in which we found symbionts in all three host species, with the smallest individuals the plantigrades of $B$. puteoserpentis with a shell length of $432 \mu \mathrm{m}, B$. azoricus with a shell length of $510 \mu \mathrm{m}$ and " $B$ ". childressi with a shell length of $383 \mu \mathrm{m}$. In these plantigrades, we observed symbionts in epithelial cells of the gill filaments, mantle, foot and retractor muscle (Figure $2 \mathrm{~b}$, e, h and j-m). Following symbiont colonization, the gill tissue showed the colonization pattern known from adult animals: the majority of gill cells were bacteriocytes without microvilli or cilia, whereas the only gill cells without symbionts were those at the ventral ends of the gill filaments and at the frontal-tolateral zones along the length of the filaments, as well as the intercalary cells (Figure S7, S8 and S10). In addition, the epithelial tissues of the mantle, foot and retractor muscles also had symbionts in all three host species (Figure $2 \mathrm{c}$, f and i). We never observed other bacteria besides the two symbionts in any of the developmental stages, including the intranuclear parasite that infects these mussels, based on FISH analyses with symbiont-specific and eubacterial probes, and TEM analyses of symbiont morphology (Figure 2, Figure 3, Figure S12 and Figure S13).

The good preservation of $B$. puteoserpentis specimens allowed us to analyse the process of symbiont colonization in this species. The first visible evidence of symbiont colonization was the presence of only a few bacterial cells in epithelial cells of plantigrades (Figure 2b, e, f, j-m). Bacterial density per gill cell was the lowest in plantigrades with $13.7 \%$ of the host cell area occupied by symbionts, but steadily increased in the later developmental stages, reaching up to $29.0 \%$ in the post-larval stage and $32.1 \%$ in adult mussels (Table S7). With the onset of symbiont colonization, we observed phagolysosomal digestion of the symbionts, in all epithelial cells, even those with only very few symbionts (Figure $2 \mathrm{~b}-\mathrm{c}$ and $\mathrm{e}-\mathrm{f}$ ). The process of symbiont colonization appeared to be extremely rapid. Nearly all plantigrades had either no symbionts at all, or all of their epithelial tissues were colonized. Only in two out of seven individuals, we occasionally observed SOX and MOX symbionts that were not completely engulfed by the host's apical cell membrane, which we interpreted as on-going colonization (Figure $2 \mathrm{j}-\mathrm{m}$ ). These first steps in colonization were particularly common in mantle epithelial cells, while in the same specimens the gill epithelial cells were already fully colonized (Figure 2b, e and f). Furthermore, in the cells where colonization was ongoing, we observed cells that were colonized only by SOX (Figure $2 \mathrm{e}$ ), or by both SOX and MOX (Figure $2 \mathrm{~h}$ ), but we never observed cells that were only colonized by MOX symbionts. 

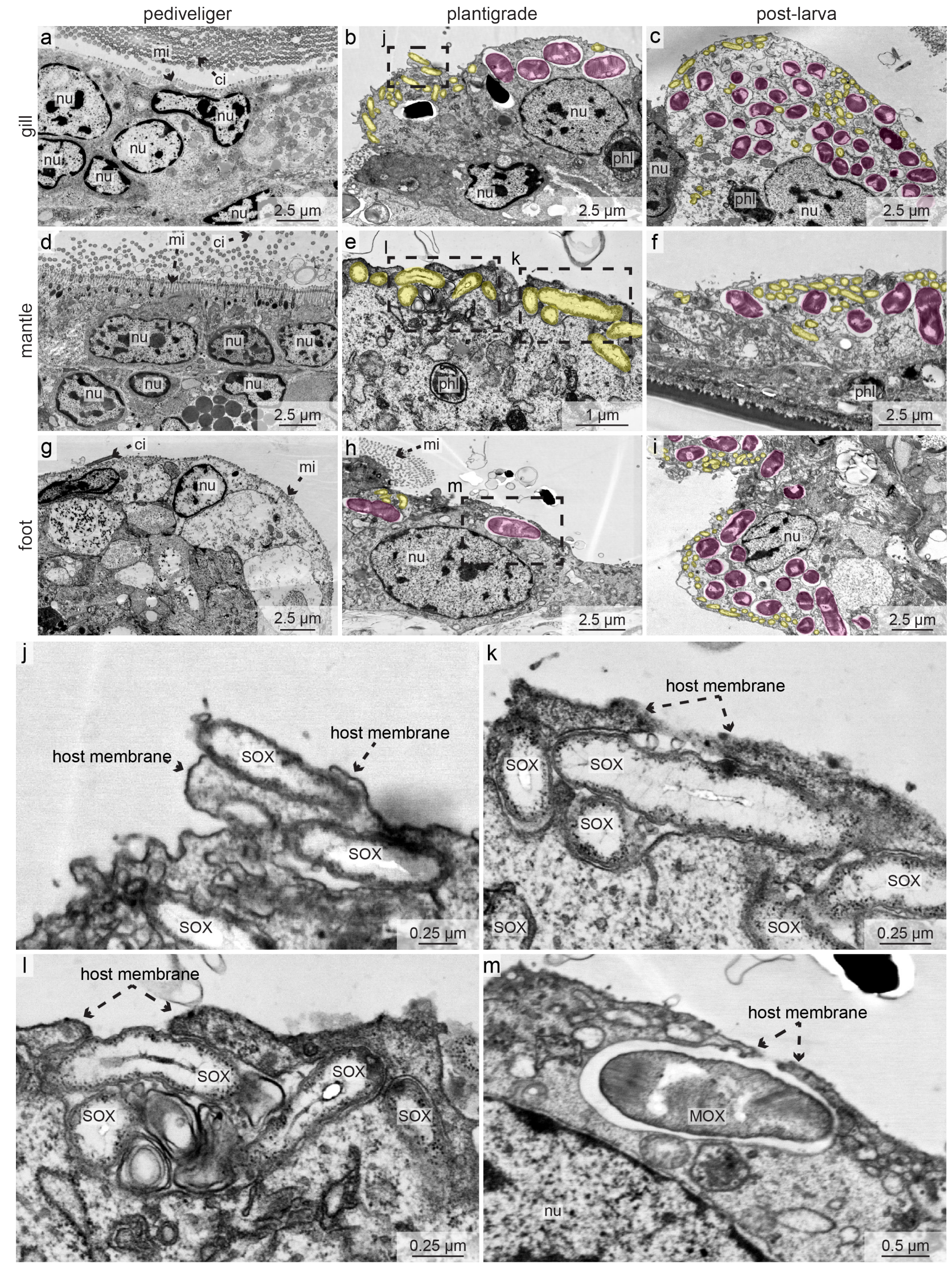

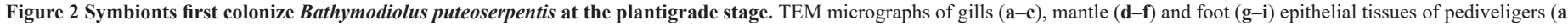

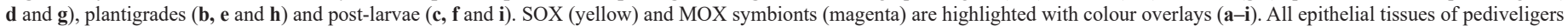

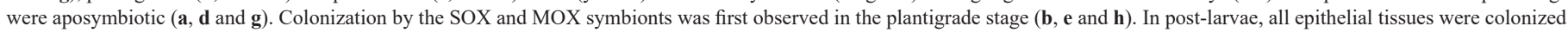

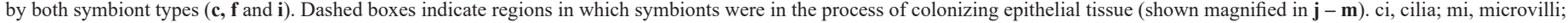
MOX, methane-oxidizing symbiont; nu, nucleus; phl, phagolysosome; SOX, sulphur-oxidizing symbiont. For raw image data see Supplement Figure S14. 


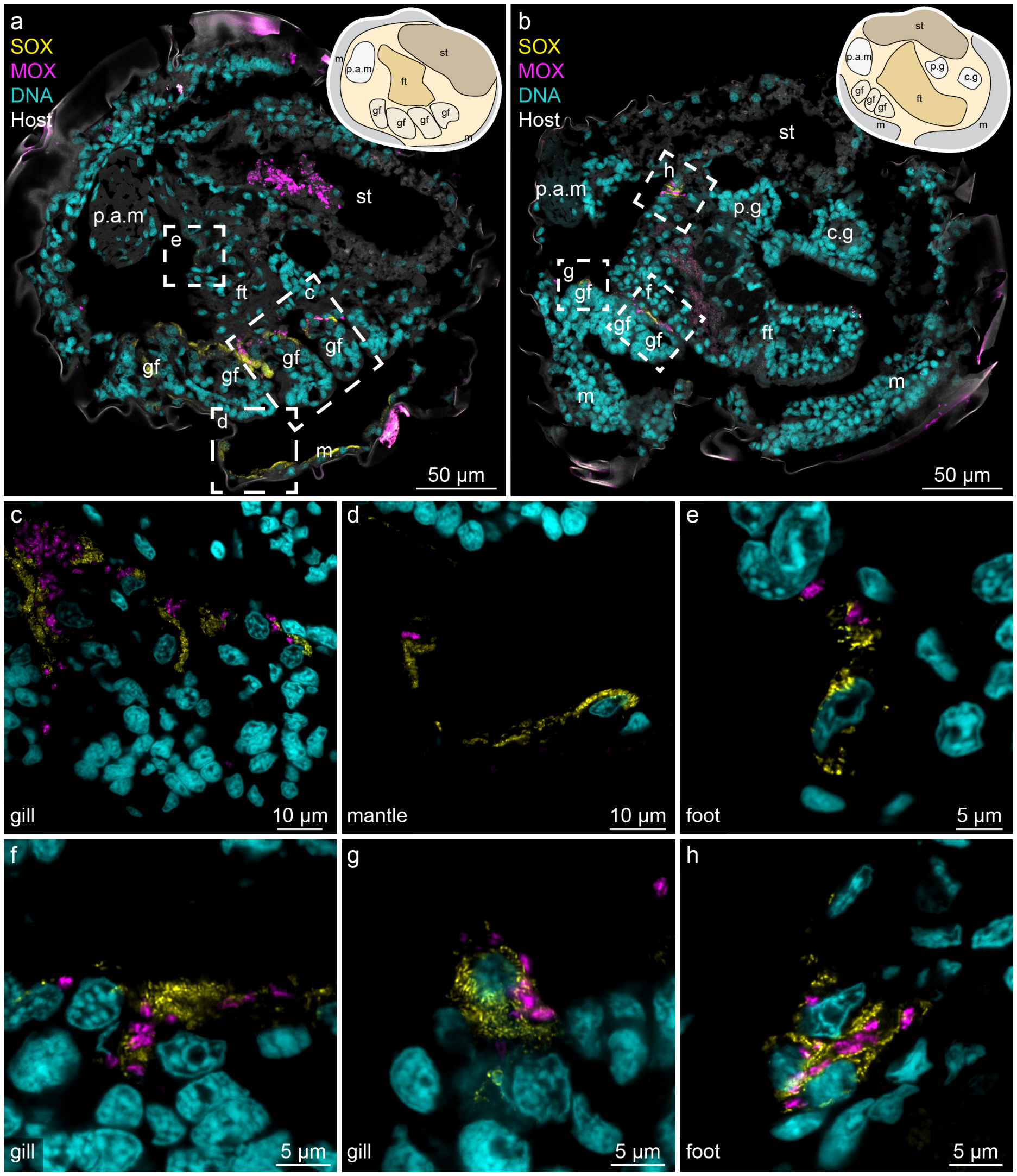

Figure 3 SOX and MOX symbionts colonize all epithelial tissues in Bathymodiolus puteoserpentis post-larvae. False-coloured FISH images show probes specific for SOX (yellow, BMARt-193) and MOX symbionts (magenta, BMARm-845) and host nuclei stained with DAPI (cyan). Sagittal cross sections of two different individuals (a and b) show SOX and MOX symbionts in the gill, foot and mantle epithelia. A schematic drawing of the anatomy is provided in the top right corner for both images. To visualize host tissues, its autofluorescence is shown in grey in a and $\mathbf{b}$. Dashed boxes indicate magnified regions of the colonized gill, mantle and foot region shown in $\mathbf{c}-\mathbf{h}$. c.g, cerebral ganglion; ft, foot; $\mathrm{m}$, mantle; gf, gill filament; p.a.m, posterior adductor muscle; p.g, pedal ganglion; st, stomach. 


\section{Discussion}

\section{Post-metamorphosis development in Bathymodiolus deviates from the mytilid blueprint}

Shell measurements are commonly used to determine the developmental stage of bivalves [14], but our study shows that these are not a reliable characteristic. Our analyses of shell lengths in Bathymodiolus developmental stages revealed an overlap in size of $50 \mu \mathrm{m}$ between pediveligers and plantigrades, as well as between plantigrades and post-larvae. The inconsistency in shell lengths between different developmental stages of Bathymodiolus indicates that initiation of metamorphosis is not size dependent and that these mussels are able to delay their metamorphosis while continuing to grow. Such a delay could be due to a lack of settlement cues and/or limited nutrition, similar to what is known from M. edulis [30]. Delaying metamorphosis would favour dispersal, potentially leading to an increase in geographic distribution and the colonization of new and remote habitats.

The pre-metamorphosis development of Bathymodiolus mussels is very similar to that of their well-studied shallow water relative M. edulis [16, 27, 30]. The pediveligers of both Bathymodiolus and Mytilus have a large velum, foot, mantle epithelium, digestive system, central nerve system and two preliminary gill baskets consisting of three to five gill buds [16]. During the metamorphosis of Bathymodiolus mussels, the velum is degraded, organs within the mantle cavity are rearranged and the lipid vesicles in the digestive tract are reduced. In early developmental stages of mussels of the families Mytilidae and Teredinidae, lipid vesicles serve as storage compounds to sustain the energy-intensive metamorphosis process $[16,31]$, and they are likely to have a similar function in Bathymodiolus. Furthermore, these lipid vesicles could provide energy for supporting movement of the pediveligers during their search for sites to settle $[32,33]$.

Although early development appears to be conserved between Bathymodiolus mussels and their shallow water relatives, marked differences occur as soon as symbiont colonization begins. All colonized epithelial cells lost not only their microvilli but also their cilia, and developed a hypertrophic habitus, as previously documented for bacteriocytes of juveniles and adults [28, 29]. Similar remodelling of the cell surface and induction of the loss of cilia and microvilli has been reported for many bacteria invading a wide range of epithelia [34-36]. Our correlative analyses demonstrate that these cell surface modifications serve as reliable markers for the state of symbiont colonization.

Although it has been known for several decades that the symbionts of Bathymodiolus supply them with nutrition, nothing was known about how this affects the development of the digestive system in these hosts. We observed a streamlining of the digestive system after completion

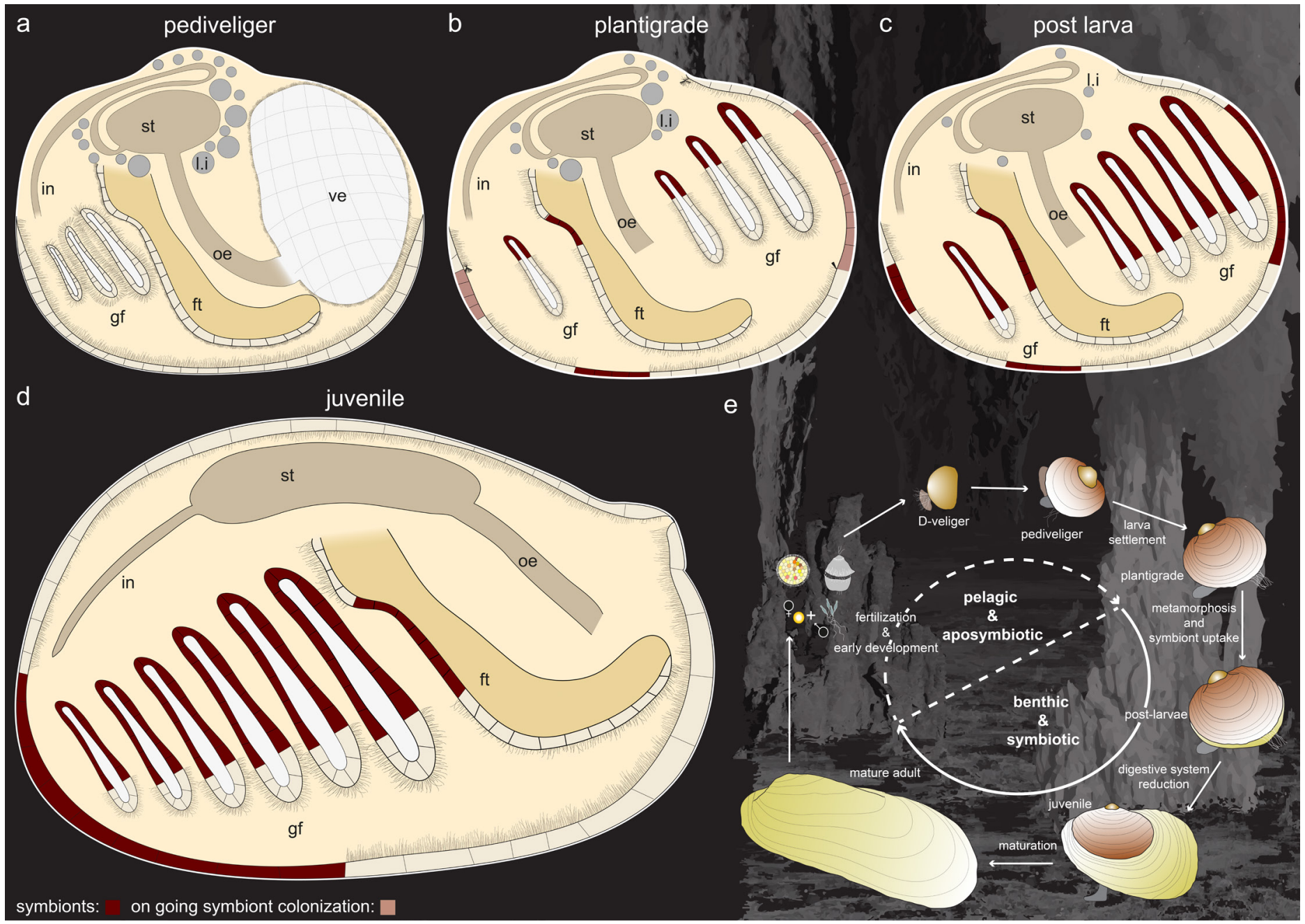

Figure 4 Summary of symbiont colonization and development of bathymodiolin mussels. Pediveliger are aposymbiotic (a), and symbiont colonization begins in plantigrades (b). By the post-larval (c) and juvenile (d) stage, all epithelial tissues are fully colonized by symbionts. The digestive system is reduced between the post-larva and juvenile stages, changing from a looped to a straight morphology. (e) Schematic of the hypothetical life cycle of bathymodiolin mussels indicating the aposymbiotic pelagic developmental stages and the symbiotic benthic developmental stages. ft, foot; gf, gill filament; in, intestine; l.i, lipid inclusion; oe, oesophagus. 
of metamorphosis in all three species (Figure 4). The stomach and the intestine straightened and the digestive system changed from the complex looped type found in Mytilus to the straight type seen in Bathymodiolus adults (Table S8, [37, 38]). Such change in morphology is striking, as in mytilids no further morphological changes occur after metamorphosis Conspicuously, in Bathymodiolus this remodelling of the digestive system did not coincide with the first stages of symbiont colonization or metamorphosis, but rather occurred during the transition from post-larvae to the juvenile stage, well after metamorphosis and only when these hosts had become fully colonized by their symbionts (Figure 4). We hypothesize that the streamlining of the digestive system is induced by the shift in nutrition of these hosts. In general, the morphology of an animal's gastrointestinal tract reflects its food sources. Animals that digest complex foods possess enlarged compartments and lengthened gastrointestinal structures to slow down the flow of digested material and increase the breakdown of complex molecules [39]. We postulate that the first life stages of Bathymodiolus rely on filter feeding and require a complex intestine to digest their diverse diet. Once they shift from filter feeding to obtaining most of their nutrition from

intracellular symbionts, the morphology of the digestive tract changes. The streamlining of the digestive tract could be an evolutionary strategy to reduce the energy needed for maintaining the digestive tract once the majority of nutrition is covered by intracellular digestion of symbionts in the bacteriocytes. It is interesting to note that adult bathymodiolin mussels of the closely-related genus Vulcanidas that occur in shallow waters close to the photic zone (140 m compared to 1000-2500 m depth for the samples studied here) have a pronounced looped intestine [40]. With more food input from the photic zone, filter feeding might play a greater role in the nutrition of Vulcanidas mussels, in contrast to the three Bathymodiolus species analysed in this study. This raises the question whether streamlining of the digestive tract is a conserved developmental trait among Bathymodiolus species, or if the environment and access to external food sources dictates this post-metamorphosis development.

\section{Symbiont colonization begins during the plantigrade stage as soon as the velum is degraded}

As highlighted by Laming, Gaudron [7], how and when Bathymodiolus mussels acquire their symbionts has remained, as yet, unclear. Here we used correlative imaging analyses to reveal that the early developmental stages of three Bathymodiolus species were aposymbiotic, and narrowed the window of symbiont acquisition down to the plantigrade stage of these hosts (Figure 4). Our analyses revealed that the symbionts colonize the gills only after the velum is lost. As long as the velum is present and active, particles from the surrounding seawater are either transported directly into the digestive system or expelled from the mussel. In $M$. edulis, once the velum is degraded the gill filaments separate further from each other and take over the task of sorting food particles and generating a water current $[16,27]$. In the late plantigrade stage of Bathymodiolus, we identified a similar increase of space between the gill filaments. It is likely that this morphological change, together with the onset of gill water filtering and particle sorting, is essential for allowing the mussel symbionts to adhere to the gill epithelium and initiate colonization.

The initial colonization of the host by their symbionts appears to be rapid, based on our observation that 22 out of 24 B. puteoserpentis individuals were either completely aposymbiotic or fully colonized, and the first stages of symbiont colonization were only visible in two plantigrades. As we were working with preserved samples that represent a snapshot of development, the chance of observing a process depends on how often it occurs and how long it takes. The less frequent or the faster a process happens, the smaller the chance of observing it. We therefore conclude that symbiont colonization occurs rapidly in Bathymodiolus, given the small percentage of individuals in which we observed the first steps of colonization. This could reflect the importance for these mussels to quickly acquire symbionts once they have settled because of the lack of energy-rich planktonic nutrition in their environment [41], and the consumption of their internal energy reserves.

In post-larvae and juveniles, the symbionts occur in epithelial cells of the gills, mantle, foot and retractor muscle [14, 42, 43]. Previous work suggested that the symbionts first colonize the mantle epithelia, and from there colonize gill cells as the first gill filaments are formed from mantle tissues [42]. Our data contradicts this assumption, as the gills had already begun to develop in pediveligers before the onset of symbiont colonization. Furthermore, in two B. puteoserpentis specimens we detected fully colonized gills, while the mantle tissue was still in the process of being colonized. Our findings indicate that symbionts first colonize gill epithelial cells before colonizing other epithelial tissues, and that the SOX symbionts colonize individual host cells first, before the MOX.

Although all Bathymodiolus individuals in this study were collected from mussel beds on the sea floor, the pediveligers were always aposymbiotic. We therefore assume that these early planktonic larval stages were in the process of settling on the sea floor. Recent work has highlighted how bacteria can induce settlement and metamorphosis in marine invertebrates [44]. It is tempting to speculate that the symbiontlike bacteria we observed on the larval shells, or microorganisms in the mussel beds, including possible free-living forms of the symbionts, play a role in inducing the settlement and metamorphosis of Bathymodiolus mussels.

Our analyses revealed that Bathymodiolus larvae are aposymbiotic during their planktonic phase and first acquire their symbionts when they transition to a benthic lifestyle. This acquisition of symbionts after settlement allows the mussels to recruit locally adapted symbionts. As the geochemistry of vent and seep environments varies strongly across temporal and spatial scales [45], recruiting locally adapted symbiont populations would confer a strong selective advantage to these hosts. Indeed, recent studies have revealed that Bathymodiolus mussels host multiple strains of symbionts that vary in key functions, such as the use of energy and nutrient sources, electron acceptors and viral defence mechanisms $[46,47]$. By acquiring their symbionts from the sites where they settle, Bathymodiolus mussels can establish symbioses with those strains that are best adapted to the local environment.

\section{Conclusion and outlook}

The correlative imaging workflow we used in this study revealed the intricate developmental processes from the subcellular to the whole animal scale that are triggered when deep-sea mussels acquire their symbionts. Our analyses revealed the narrow window in which symbiont acquisition begins and revealed the morphological changes of the digestive system following symbiont uptake. Given that we never observed bacterial morpho- or phylotypes other than the known SOX and MOX symbionts, even in the earliest larval life stages, strong recognition mechanisms must ensure this high specificity. Now that we have identified when and how symbiont colonization takes place in Bathymodiolus, a spatial and temporal transcriptomic approach could shed light on the underlying molecular mechanisms of symbiont recognition, acquisition and maintenance, and further our understanding of the interwoven dialogue between animal hosts and their microbial symbionts.

\section{Data accessibility}

LM-data and $\mu$ CT-data is available on figshare. The DOIs are listed in Table S1. 
All supplementary videos are available with the following DOIs:

Video S1: https://doi.org/10.6084/m9.figshare.13049765.v2

Video S2: https://doi.org/10.6084/m9.figshare.13049807.v1

Video S3: https://doi.org/10.6084/m9.figshare.13049870.v1

Video S4: https://doi.org/10.6084/m9.figshare.13049882.v1

Video S5: https://doi.org/10.6084/m9.figshare.13049993.v1

\section{Authors' contributions}

M.F., N.L. and N.D. conceived this study. M.F. and N.L. wrote the manuscript, with support from N.D., and contributions and revisions from all other co-authors. M.F. performed the light and fluorescence microscopy, analysed the light, TEM, fluorescence and $\mu \mathrm{CT}$ datasets, reconstructed the $3 \mathrm{D}$ models, designed the figures, and produced the videos. B.G. helped with the $3 \mathrm{D}$ reconstructions and $\mu \mathrm{CT}$-measurements. J.U.H. performed the $\mu \mathrm{CT}$ measurements with help from B.G. and M.F. and reconstructed the $\mu$ CT-datasets. N.L. did the TEM re-sectioning and measurements.

\section{Competing interests}

We declare no competing interests.

\section{Funding}

Funding was provided by the Max Planck Society, the MARUM Cluster of Excellence 'The Ocean Floor' (Deutsche Forschungsgemeinschaft (German Research Foundation) under Germany's Excellence Strategy EXC-2077 - 39074603), a Gordon and Betty Moore Foundation Marine Microbial Initiative Investigator Award (grant no. GBMF3811 to N.D.) and a European Research Council Advanced Grant (BathyBiome, Grant 340535 to N.D.). $\mu \mathrm{CT}$ measurements were performed at the DESY under the proposal IDs: 20170337 and 20180295.

\section{Acknowledgements}

We thank the captains, crew members and ROV pilots of the cruises M126, M82-3 and NA58. We thank Christian Borowski and Stéphane Hourdez for their valuable contributions to collecting mussel larvae. Furthermore, we gratefully acknowledge Wiebke Ruschmeier for her help in the lab. We would like to thank all those involved in supporting us at the DESY at the P05 beamline of PETRA III (Helmholtz-Zentrum Hereon, Geesthacht, Germany). We would like to thank Benjamin Cooper (Max-Planck Institute for Experimental Medicine, Göttingen) for preliminary sample preparation and Bernhard Ruthensteiner (Zoologische Staatsammlung München) und Frank Melzner (GEOMAR, Kiel) for fruitful discussions.

\section{References}

[1] McFall-Ngai, M., Hadfield, M.G., Bosch, T.C.G., Carey, H.V., Domazet-Lošo, T., Douglas, A.E., Dubilier, N., Eberl, G., Fukami, T., Gilbert, S.F., et al. 2013 Animals in a bacterial world, a new imperative for the life sciences. Proceedings of the National Academy of Sciences 110, 3229-3236. (doi:10.1073/pnas.1218525110).

[2] Dubilier, N., Bergin, C. \& Lott, C. 2008 Symbiotic diversity in marine animals: the art of harnessing chemosynthesis. Nature Reviews: Microbiology 6, 725-740. (doi:10.1038/nrmicro1992).

[3] DeChaine, E. \& Cavanaugh, C.M. 2005 Symbioses of methanotrophs and deep-sea mussels (Mytilidae: Bathymodiolinae). Progress in Molecular and Subcellular Biology 41, 227-249. (doi:10.1007/3-540-28221-1_11).

[4] Bright, M. \& Bulgheresi, S. 2010 A complex journey: transmission of microbial symbionts. Nature Reviews: Microbiology 8, 218-230. (doi:10.1038/nrmicro2262).

[5] McFall-Ngai, M.J. 2014 The importance of microbes in animal development: lessons from the squid-vibrio symbiosis. Annual Review of Microbiology 68, 177-194. (doi:10.1146/annurevmicro-091313-103654).

[6] Nussbaumer, A.D., Fisher, C.R. \& Bright, M. 2006 Horizontal endosymbiont transmission in hydrothermal vent tubeworms. Nature 441, 345-348. (doi:10.1038/nature04793).

[7] Laming, S.R., Gaudron, S.M. \& Duperron, S. 2018 Lifecycle Ecology of Deep-Sea Chemosymbiotic Mussels: A Review. Frontiers in Marine Science 5. (doi:10.3389/fmars.2018.00282).

[8] Fontanez, K.M. \& Cavanaugh, C.M. 2014 Evidence for horizontal transmission from multilocus phylogeny of deep-sea mussel (Mytilidae) symbionts. Environmental Microbiology 16, 3608-3621. (doi:10.1111/1462-2920.12379).

[9] Won, Y.J., Hallam, S.J., O’Mullan, G.D., Pan, I.L., Buck, K.R. \& Vrijenhoek, R.C. 2003 Environmental Acquisition of Thiotrophic Endosymbionts by Deep-Sea Mussels of the Genus Bathymodiolus. Applied and Environmental Microbiology 69, 6785-6792. (doi:10.1128/ aem.69.11.6785-6792.2003).

[10] Won, Y.J., Jones, W.J. \& Vrijenhoek, R.C. 2008 Absence of cospeciation between deepsea mytilids and their thiotrophic endosymbionts. Journal of Shellfish Research 27, 129-138. (doi:10.2983/0730-8000(2008)27[129:AOCBDM]2.0.CO;2).

[11] Russell, S.L., Pepper-Tunick, E., Svedberg, J., Byrne, A., Ruelas Castillo, J., Vollmers, C., Beinart, R.A. \& Corbett-Detig, R. 2020 Horizontal transmission and recombination maintain forever young bacterial symbiont genomes. PLOS Genetics 16, e1008935. (doi:10.1371/journal. pgen.1008935).

[12] Laming, S.R., Duperron, S., Cunha, M.R. \& Gaudron, S.M. 2014 Settled, symbiotic, then sexually mature: adaptive developmental anatomy in the deep-sea, chemosymbiotic mussel Idas modiolaeformis. Marine Biology 161, 1319-1333. (doi:10.1007/s00227-014-2421-y).

[13] Laming, S.R., Duperron, S., Gaudron, S.M., Hilario, A. \& Cunha, M.R. 2015 Adapted to change: The rapid development of symbiosis in newly settled, fast-maturing chemosymbiotic mussels in the deep sea. Marine Environmental Research 112, 100-112. (doi:10.1016/j.marenvres.2015.07.014).

[14] Salerno, J.L., Macko, S.A., Hallam, S.J., Bright, M., Won, Y.J., McKiness, Z. \& Van Dover, C.L. 2005 Characterization of symbiont populations in life-history stages of mussels from chemosynthetic environments. Biological Bulletin 208, 145-155. (doi:10.2307/3593123).

[15] Thubaut, J., Puillandre, N., Faure, B., Cruaud, C. \& Samadi, S. 2013 The contrasted evolutionary fates of deep-sea chemosynthetic mussels (Bivalvia, Bathymodiolinae). Ecology and Evolution 3, 4748-4766. (doi:10.1002/ece3.749).

[16] Bayne, B.L. 1971 Some morphological changes that occur at the metamorphosis of the larvae of Mytilus edulis. In The Fourth European Marine Biology Symposium (pp. 259-280.

[17] Geier, B., Oetjen, J., Ruthensteiner, B., Polikarpov, M., Gruber-Vodicka, H. \& Liebeke, M. 2021 Connecting structure and function from organisms to molecules in small animal symbioses through chemo-histo-tomography. bioRxiv, 2020.2009.2028.316802. (doi:10.1101/2020.09.28.316802).

[18] Handschuh, S., Baeumler, N., Schwaha, T. \& Ruthensteiner, B. 2013 A correlative approach for combining microCT light and transmission electron microscopy in a single 3D scenario. Frontiers in Zoology 10. (doi:10.1186/1742-9994-10-44).

[19] Montanaro, J., Gruber, D. \& Leisch, N. 2016 Improved ultrastructure of marine invertebrates using non-toxic buffers. PeerJ 4, e1860. (doi:10.7717/peerj.1860).

[20] Stoecker, K., Dorninger, C., Daims, H. \& Wagner, M. 2010 Double labeling of oligonucleotide probes for fluorescence in situ hybridization (DOPE-FISH) improves signal intensity and increases rRNA accessibility. Applied and Environmental Microbiology 76, 922-926. (doi:10.1128/ AEM.02456-09).

[21] Wilde, F., Ogurreck, M., Greving, I., Hammel, J.U., Beckmann, F., Hipp, A., Lottermoser, L., Khokhriakov, I., Lytaev, P., Dose, T., et al. 2016 Micro-CT at the imaging beamline P05 at PETRA III. AIP Conference Proceedings 1741, 030035. (doi:10.1063/1.4952858).

[22] Geier, B., Franke, M., Ruthensteiner, B., Porras, M.Á.G., Gruhl, A., Wörmer, L., Moosmann, J., Hammel, J.U., Dubilier, N., Leisch, N., et al. 2019 Correlative 3D anatomy and spatial chemistry in animal-microbe symbioses: developing sample preparation for phase-contrast synchrotron radiation based micro-computed tomography and mass spectrometry imaging. In SPIE Optical Engineering + Applications (eds. B. Müller \& G. Wang), SPIE.

[23] Moosmann, J., Ershov, A., Weinhardt, V., Baumbach, T., Prasad, M.S., LaBonne, C., Xiao, X., Kashef, J. \& Hofmann, R. 2014 Time-lapse X-ray phase-contrast microtomography for in vivo imaging and analysis of morphogenesis. Nature Protocols 9, 294. (doi:10.1038/nprot.2014.033).

[24] van Aarle, W., Palenstijn, W.J., De Beenhouwer, J., Altantzis, T., Bals, S., Batenburg, K.J. \& Sijbers, J. 2015 The ASTRA Toolbox: A platform for advanced algorithm development in electron tomography. Ultramicroscopy 157, 35-47. (doi:10.1016/j.ultramic.2015.05.002).

[25] van Aarle, W., Palenstijn, W.J., Cant, J., Janssens, E., Bleichrodt, F., Dabravolski, A., De Beenhouwer, J., Joost Batenburg, K. \& Sijbers, J. 2016 Fast and flexible X-ray tomography using the ASTRA toolbox. Optics Express 24, 25129-25147. (doi:10.1364/oe.24.025129).

[26] Cardona, A., Saalfeld, S., Schindelin, J., Arganda-Carreras, I., Preibisch, S., Longair, M., Tomancak, P., Hartenstein, V. \& Douglas, R.J. 2012 TrakEM2 Software for Neural Circuit Reconstruction. PloS One 7, e38011. (doi:10.1371/journal.pone.0038011).

[27] Cannuel, R., Beninger, P.G., Mc Combie, H. \& Boudry, P. 2009 Gill Development and Its Functional and Evolutionary Implications in the Blue Mussel Mytilus edulis. Biolobical Bulletin 217, 173-188. (doi:10.1086/BBLv217n2p173).

[28] Fisher, C.R., Childress, J.J., Oremland, R.S. \& Bidigare, R.R. 1987 The importance of methane and thiosulfate in the metabolism of the bacterial symbionts of two deep-sea mussels. Marine Biology 96, 59-71. (doi:10.1007/BF00394838).

[29] Wentrup, C., Wendeberg, A., Schimak, M., Borowski, C. \& Dubilier, N. 2014 Forever competent: deep-sea bivalves are colonized by their chemosynthetic symbionts throughout their lifetime. Environmental Microbiology 16, 3699-3713. (doi:10.1111/1462-2920.12597).

[30] Bayne, B.L. 1965 Growth and the delay of metamorphosis of the larvae of Mytilus edulis (L.). Ophelia 2, 1-47. (doi:10.1080/00785326.1965.10409596).

[31] Gallager, S.M., Mann, R. \& Sasaki, G.C. 1986 Lipid as an index of growth and viability in three species of bivalve larvae. Aquaculture 56, 81-103. (doi:10.1016/0044-8486(86)90020-7).

[32] Breusing, C., Biastoch, A., Drews, A., Metaxas, A., Jollivet, D., Vrijenhoek, Robert C., Bayer, T., Melzner, F., Sayavedra, L., Petersen, Jillian M., et al. 2016 Biophysical and Population Genetic Models Predict the Presence of "Phantom" Stepping Stones Connecting Mid-Atlantic Ridge Vent Ecosystems. Current Biology 26, 2257-2267. (doi:10.1016/j.cub.2016.06.062).

[33] Distel, D.L., Baco, A.R., Chuang, E., Morrill, W., Cavanaugh, C. \& Smith, C.R. 2000 Do mussels take wooden steps to deep-sea vents? Nature 403, 725-726. (doi:10.1038/35001667). 
[34] Kaper, J.B., Nataro, J.P. \& Mobley, H.L.T. 2004 Pathogenic Escherichia coli. Nature Reviews: Microbiology 2, 123-140. (doi:10.1038/nrmicro818).

[35] Quarmby, L.M. 2004 Cellular Deflagellation. In International Review of Cytology (pp. 47-91, Academic Press.

[36] Tubiash, H.S., Chanley, P.E. \& Leifson, E. 1965 Bacillary Necrosis, a Disease of Larval and Juvenile Bivalve Mollusks I. Etiology and Epizootiology. Journal of Bacteriology 90, 1036.

[37] Le Pennec, M., Benninger, P.G. \& Herry, A. 1995 Feeding and digestive adaptations of bivalve molluscs to sulphide-rich habitats. Comparative Biochemistry and Physiology 111, 183-189. (doi:10.1016/0300-9629(94)00211-B).

[38] Von Cosel, R., Comtet, T. \& Krylova, E.M. 1999 Bathymodiolus (Bivalvia: Mytilidae) from Hydrothermal Vents on the Azores Triple Junction and the Logatchev Hydrothermal Field, MidAtlantic Ridge. The Veliger 42, 218-248.

[39] Karasov, W.H. \& Douglas, A.E. 2013 Comparative digestive physiology. Comprehensive Physiology 3, 741-783. (doi:10.1002/cphy.c110054).

[40] Von Cosel, R. \& Marshall, B.A. 2010 A new genus and species of large mussel (Mollusca: Bivalvia: Mytilidae) from the Kermadec Ridge. Records of the Musuem of New Zwaland Te Papa 21, 15.

[41] Page, H., Fisher, C. \& Childress, J. 1990 Role of filter-feeding in the nutritional biology of a deep-sea mussel with methanotrophic symbionts. Marine Biology 104, 251-257. (doi:10.1007/ BF01313266)

[42] Streams, M.E., Fisher, C.R. \& Fiala-Médioni, A. 1997 Methanotrophic symbiont location and fate of carbon incorporated from methne in a hydrocabon seep mussel. Marine Biology 129, 465-476. (doi:10.1007/s002270050187).

[43] Wentrup, C., Wendeberg, A., Huang, J.Y., Borowski, C. \& Dubilier, N. 2013 Shift from widespread symbiont infection of host tissues to specific colonization of gills in juvenile deep-sea mussels. The ISME Journal 7, 1244-1247. (doi:10.1038/ismej.2013.5).

[44] Shikuma, N.J., Pilhofer, M., Weiss, G.L., Hadfield, M.G., Jensen, G.J. \& Newman, D.K. 2014 Marine Tubeworm Metamorphosis Induced by Arrays of Bacterial Phage Tail-Like Structures. Science 343, 529. (doi:10.1126/science.1246794).

[45] Desbruyères, D., Almeida, A., Biscoito, M., Comtet, T., Khripounoff, A., Le Bris, N., Sarradin, P.M. \& Segonzac, M. 2000 A review of the distribution of hydrothermal vent communities along the northern Mid-Atlantic Ridge: dispersal vs. environmental controls. In Island, Ocean and Deep-Sea Biology (eds. M.B. Jones, J.M.N. Azevedo, A.I. Neto, A.C. Costa \& A.M.F. Martins), pp. 201-216. Dordrecht, Springer Netherlands.

[46] Ansorge, R., Romano, S., Sayavedra, L., Porras, M.Á.G., Kupczok, A., Tegetmeyer, H.E., Dubilier, N. \& Petersen, J. 2019 Functional diversity enables multiple symbiont strains to coexist in deep-sea mussels. Nature Microbiology 4, 2487-2497. (doi:10.1038/s41564-019-0572-9).

[47] Romero Picazo, D., Dagan, T., Ansorge, R., Petersen, J.M., Dubilier, N. \& Kupczok, A. 2019 Horizontally transmitted symbiont populations in deep-sea mussels are genetically isolated. The ISME Journal 13, 2954-2968. (doi:10.1038/s41396-019-0475-z). 